\title{
Cyclical disturbance of diabetic control in girls before the menarche
}

\author{
K G E Brown, C W Darby, S H Ng
}

\begin{abstract}
Seven diabetic girls who presented with cyclical disturbance of diabetic control before the menarche are described. In six girls cyclical hyperglycaemia occurred and in one cyclical hypoglycaemia. The index case is described in detail, and is then included in a description of the main clinical features of all seven cases. Cyclical disturbance of diabetic control may present in diabetic girls from age 9 years onwards. Home blood glucose monitoring records may reveal cyclical disturbance, usually hyperglycaemia, and usually occurring at 21-34 day intervals and lasting for two to five days. Serious illnesses and hospital admission can be averted by educating parents to make appropriate changes to insulin regimen or diet. Our hypothesis is that the disturbance of diabetic control is caused by the onset of cyclical hormonal changes, a 'menstrual' cycle before menstruation. The precise mechanism for the changes in carbohydrate tolerance is unknown.
\end{abstract}

In adult insulin dependent diabetic women an association has been described between menstruation and disturbance of diabetic control, ${ }^{1}$ and between menstruation and hospital admission for diabetic ketoacidosis. ${ }^{12}$ In this paper we present the case histories of seven diabetic girls who experienced cyclical disturbance of diabetic control before the menarche.

\section{Case reports}

INDEX CASE

This girl had diabetes mellitus diagnosed at the age of $7 \cdot 6$ years. She was well controlled on a twice daily insulin (Actrapid/Monotard, Novo Nordisk) regimen with no hospital admissions until two months after her 13th birthday, 10 months before the onset of menstruation. In December 1981 after a 12 hour history of intense thirst followed by profuse vomiting, she was admitted in severe ketoacidosis. She responded rapidly to standard treatment, a diagnosis of 'viral gastritis' was made, and she was discharged after 48 hours on her usual insulin regimen in slightly increased dose. Four weeks later she again developed a sudden onset of nausea followed by profuse vomiting. She was immediately admitted, once again in severe ketoacidosis, which responded well to standard treatment.

The possible significance of the four week interval as a cyclical hormonal event was explained to her mother. She was advised to test the blood glucose frequently from around the 26th day after the onset of the last episode of disturbance of diabetic control, and to give extra Actrapid insulin as necessary. A pattern emerged of sudden increases in blood glucose concentrations for two days at $\mathbf{2 6}$ day intervals. At these times the total daily dose of insulin was increased by between $15 \%$ and $30 \%$. This involved increasing the usual morning and evening Actrapid doses and also giving midday and/or midnight Actrapid injections as necessary, over a two day period, to control the blood glucose readings. Despite nine further episodes of cyclical diabetic disturbance, no further hospital admissions were needed. The menarche occurred in October 1982. The cyclical disturbance stopped completely and there was no hyperglycaemia in association with established periods.

\section{CLINICAL FEATURES OF ALL SEVEN GIRLS} (INCLUDING INDEX CASE)

The salient clinical features are summarised in the table. At the time of the development of cyclical diabetic disturbance, one girl was at Tanner stage 1 but the other six were in early puberty at Tanner stage $2 .^{3}$ In six out of seven girls the episodes started with abdominal symptoms, vomiting in four, and abdominal pain and diarrhoea in two.

In six girls cyclical hyperglycaemia occurred and five of these girls were admitted to hospital for a total of 11 episodes of diabetic ketoacidosis. In four girls admitted to hospital with ketoacidosis the white cell count was above $15.0 \times 10^{9} / 1$ and fever was present. However no evidence of infection was found and they recovered without antibiotic treatment.

Clinical features of seven girls with cyclical disturbance of diabetic control

\begin{tabular}{|c|c|c|}
\hline & Mean & Range \\
\hline Age at diagnosis of diabetes (years) & 6.8 & $1 \cdot 9-11 \cdot 2$ \\
\hline $\begin{array}{l}\text { disturbance (years) } \\
\text { Cycle length in days between }\end{array}$ & $10 \cdot 8$ & $9 \cdot 7-13 \cdot 2$ \\
\hline episodes & 31 & $21-56$ \\
\hline $\begin{array}{l}\text { Duration of cyclical disturbance (days) } \\
\text { No of cyclical episodes }\end{array}$ & $\begin{array}{r}3 \\
18\end{array}$ & $\begin{array}{l}2-5 \\
7-40\end{array}$ \\
\hline $\begin{array}{l}\text { Insulin dose during time of cyclical } \\
\text { disturbance (U/kg body weight) }\end{array}$ & $1 \cdot 2$ & $1-1 \cdot 7$ \\
\hline disturbance $(n=5)^{*}$ & 10.9 & $7-15 \cdot 8$ \\
\hline $\begin{array}{l}\text { (\% of total daily dose })(n=6) \\
\text { Age at menarche }(n=6)\end{array}$ & $\begin{array}{l}20 \cdot 5 \\
13 \cdot 3\end{array}$ & $\begin{array}{c}8-36 \\
12 \cdot 5-14 \cdot 0\end{array}$ \\
\hline $\begin{array}{l}\text { Established menstrual cycle length } \\
\text { (days) }(n=6)\end{array}$ & 31 & $21-56$ \\
\hline
\end{tabular}

were measuring $\mathrm{HbA}_{\mathrm{Ic}}$; normal value $<7 \cdot 5 \%$. 
In one girl the diagnosis was made retrospectively after the menarche when it became clear that established menstrual cycle length was 56 days. The unusual cycle length and intercurrent infections had confused diagnosis, but review showed a clear pattern of hyperglycaemia every two months up to the menarche.

One girl presented with relative hypoglycaemia at 26-30 day intervals. She had always had poor diabetic control with a glycated haemoglobin $\left(\mathrm{HbA}_{\mathrm{Ic}}\right)$ around $14 \%$ (normal $<7 \cdot 5 \%)$ and blood glucose concentration in the range $11-22 \mathrm{mmol} / \mathrm{l}$. At approximately monthly intervals blood glucose dropped to around $7 \mathrm{mmol} / 1$ at which concentration she experienced hypoglycaemic symptoms. This was treated with extra carbohydrate without insulin reduction. She had a single hospital admission for one of these cyclical episodes, which was preceded by abdominal pain and vomiting. The admission blood glucose concentration was $4.4 \mathrm{mmol} / \mathrm{l}$ and the symptoms settled over 24 hours without special treatment or change in her usual insulin dosage.

In the six girls who have passed the menarche, disturbance of diabetic control has continued in association with menstruation in three, and has stopped completely in three. Menstrual cycle length is essentially the same as the cycle length between episodes of disturbance of diabetic control before the menarche.

Insulin requirements show no clear pattern of change. When insulin requirements between episodes of cyclical diabetic disturbance are compared with requirements one year after the menarche, in the index case there was a fall $(0.4 \mathrm{U} / \mathrm{kg})$, in two girls no change, and in four girls a small rise $(0 \cdot 1-0 \cdot 2 \mathrm{U} / \mathrm{kg})$. Changes in HbA $_{\text {Ic }}$ values however did show a pattern. In three girls with high values $(>10 \%)$ while cyclical diabetic disturbance was still occurring, the values fell one year after the menarche to reasonable values $(7 \cdot 5-9 \%)$. One of these three was the girl with cyclical hypoglycaemia and very poor diabetic control between episodes. The other two had the most severe cyclical diabetic disturbance and together accounted for six hospital admissions. In two girls with reasonable $\mathrm{HbA}_{\mathrm{Ic}}$ values while cyclical disturbance was occurring values were unchanged one year after the menarche.

\section{Discussion}

We first observed cyclical disturbance of diabetic control early in 1982 in the index case who had a total of 11 potentially life threatening episodes. After her menarche the serious monthly episodes of hyperglycaemia stopped completely. Over the past eight years we have observed a total of seven girls with cyclical disturbance of diabetic control before the menarche. Six of the girls experienced hyperglycaemia and one hypoglycaemia. In all the girls the cyclical disturbance presented between the ages of 9 and 14 years. During the same eight year period we have cared for 52 girls from age 9 years through to either 14 years or the menarche. The incidence of this condition in our centre is therefore $13.5 \%$ of susceptible girls.
The condition should be considered in any episode of unexplained diabetic ketoacidosis, and a raised white cell count and fever do not exclude the diagnosis. Our current policy is to give education about this condition to parents of diabetic girls from age 9 years. They are advised to watch for monthly episodes of hyperglycaemia, although the possibility of hypoglycaemia is mentioned. The possibility of the diagnosis is now often first raised by parents (this has happened in four of the last five cases) and is confirmed by inspection of the home blood glucose record book, and by careful prospective testing.

The condition is managed by parents testing blood glucose concentrations frequently from two days before the expected cyclical disturbance. They also test for ketones in the urine. All girls in the susceptible age group in Bromley are on twice daily soluble/isophane insulin, usually given as a premixed insulin (for example, Humulin M3, Lilly). For the first few episodes of diabetic disturbance parents are advised to give supplementary doses of soluble insulin with the usual morning and evening insulin if blood glucose concentration rises above $15 \mathrm{mmol} / \mathrm{l}$. They may also give extra soluble insulin before lunch and occasionally even during the night. As an initial guideline the supplementary dose of soluble insulin is based on the usual 24 hour insulin dose. If blood glucose concentration is raised above $15 \mathrm{mmol} / \mathrm{l}$, and urine ketones are $(++)$ or less, one tenth $(10 \%)$ of the 24 hour insulin dose is given. If ketones are more then $(++), 15 \%$ is given. With experience of a few cycles of diabetic disturbance the usual morning and/or evening insulin doses may also be increased, and in milder cases this may alone prove sufficient. The one girl with cyclical hypoglycaemia was managed by giving extra carbohydrate only. Reduction of insulin dosage might prove necessary if a child with more severe episodes of hypoglycaemia were to present. Our view is that the disturbance of diabetic control is associated with cyclical phenomena, similar to those occurring in the adult menstrual cycle, but preceding the menarche. The grounds for this assertion are twofold. Firstly, the cycle length of diabetic disturbance before the menarche, and the established menstrual cycle length, are identical in four cases and within two days in two cases. In this respect one girl is particularly interesting in that the condition was firmly diagnosed only in retrospect, when a 56 day menstrual cycle was established. Secondly, similar problems with diabetic control continued in association with menstruation in three cases. The seven girls described here do not differ from the rest of our clinic population in relation to overall diabetic control as reflected in $\mathrm{HbA}_{\text {Ic }}$ measurements or insulin requirements. Poor diabetic control in three girls was in large part the result of the cyclical disturbance and the $\mathrm{HbA}_{\mathrm{Ic}}$ values improved after the menarche when the cyclical disturbance stopped.

We are not aware of any previous definitive description of this condition. The only record in the literature of cyclical diabetic disturbance before the menarche is in the case reported by 
Hubble. ${ }^{4}$ He described a girl who developed diabetes at age 13 years, severe recurrent diabetic ketoacidosis from age $14 \cdot 1$ years, and the menarche at age 14.6 years. This was an exceptional case requiring up to 19200 units of insulin in one day. The severe cyclical insulin resistance continued in association with menstruation and she died during an episode of diabetic ketoacidosis aged $15 \cdot 1$ years. This case may have been an extreme example of the condition we are describing.

In non-diabetic menstruating adult women changes in carbohydrate tolerance occur, with a tendency to hypoglycaemia in the days 1-3 before menstruation and hyperglycaemia at the onset. $^{56}$ Hypoglycaemia may sometimes contribute to the premenstrual syndrome. ${ }^{7}$ In one study of 200 insulin dependent diabetic adult women interviewed, 53 noted hyperglycaemia, and 23 relative hypoglycaemia, in association with menstruation. ${ }^{1}$ Menstruation has been associated with diabetic ketoacidosis leading to hospital admission. ${ }^{12}$ Recurrent diabetic ketoacidosis has also been described with each menstruation cycle, ${ }^{47}$ in one case occurring with every menstruation over one year. ${ }^{8} \mathrm{~A}$ detailed review of the effects of the menstrual cycle on medical disorders lists more than 100 variables that fluctuate during the menstrual cycle. ${ }^{9}$ With regard to diabetes and the menstrual cycle the review concludes that 'one can only speculate as to the reasons for altered diabetic control'. It is known that sex hormones can modulate insulin receptors, and binding is higher in the follicular than in the luteal phases of the menstrual cycle. ${ }^{6}$ It has been suggested that increased insulin binding in the follicular phase is associated with hypoglycaemia ${ }^{6} 10$ and decreased binding in the luteal phase is associated with impaired carbohydrate tolerance and hyperglycaemia. ${ }^{6} 9$ This observation might explain the cyclical hyperglycaemia in six of our cases and the hypoglycaemia observed in one of our cases.

Another possible explanation for cyclical disturbance of diabetic control is that it is associated with growth. Compared with both prepubertal children and adults, increased insulin resistance during puberty has been demonstrated in diabetic and non-diabetic children, and the response to insulin is inversely correlated with 24 hour concentrations of growth hormone. ${ }^{11}$ Growth hormone surges have also been associated with the dawn phenomenon in adolescent diabetics. ${ }^{12}$ However if growth hormone is responsible for cyclical disturbance of diabetic control one would expect to see the condition in boys, and we have not. The literature contains no data showing monthly cyclical changes in growth hormone concentrations before the menarche, and in addition concentrations do not change significantly during the menstrual cycle. ${ }^{13}$ Also cyclical surges of growth hormone or other insulin antagonists would not explain cyclical hypoglycaemia. Further studies in girls with cyclical diabetic disturbance before the menarche could include ultrasound examination of the ovaries. This could establish the occurrence of cyclical follicle formation, and the relationship to the diabetic disturbance, and confirm that the disturbance is associated with a 'menstrual' cycle. Performing an euglycaemia insulin clamp procedure in mid-cycle and at the time of cyclical diabetic disturbance, together with sex hormone, gonadotrophin, and counterregulatory hormone (growth hormone, cortisol, etc) measurement, should confirm changes in insulin resistance and might elucidate mechanisms.

Why is this relatively common cyclical disturbance of diabetic control only now being described? The first reason is the operation for the past 15 years in Bromley of a special paediatric diabetic clinic with close involvement of specialist diabetes nurses, which brings together all the district's diabetic children. The second reason relates to the introduction of frequent home blood testing in our diabetic children over the last $10-15$ years. The third reason relates to the education of parents about the condition in the clinic and in a self help group which has run for 10 years.

It is important to recognise this condition, and to educate parents so that serious and life threatening disturbance of diabetic control can be prevented.

We are grateful to Lilly Industries Limited for the grant supporting one of us (CWD for one consultant session per week in paediatric diabetes.)

1 Walsh $\mathrm{CH}$, Malins JM. Menstruation and control of diabetes. BMF 1977;ii:177-9.

2 Cramer HI. Influence of menstruation on carbohydrate tolerance in diabetes mellitus. Can Med Assoc $\mathcal{F}$ 1942;47: $51-5$.

3 Tanner JM, Whitehouse RH. Castlemead Publications, 1975. (Ref 12A, Integrated Studies.)

(1954;i:1022-4.

5 Walsh CH, Walsh SJ, Wright AD, Holder G, Williams J Menstruation and diabetic control. Diabetologia 1982;23 476.

6 Grunberger G, Taylor SI, Dons RF, Gorden P. Insulin receptors in normal and disease states. Clinics in Endocrinology and Metabolism 1983;12:191-219.

7 Green $R$. Phasic insulin resistance association with the menstrual cycle and controlled by fludrocortisone: a case report. Metabolism 1958;7:90.

8 Sandstrom B. Diabetes mellitus och menstruation. Nord Med 1969;81:727-8.

9 Magos A, Studd J. Effects of the menstrual cycle on medical disorders. Br 7 Hosp Med 1985; February:68-77.

10 Reid RL Yen SSC Premenstrual syndrome. Am 7 Obstet Gynecol 1981;139:85-104.

11 Amiel SA, Sherwin RS, Simonson DC, Lauritano AA Tamborlane WV. Impaired insulin action in puberty. A contributing factor to poor glycaemic control in adolescent with diabetes. $N$ Engl f Med 1986;315:215-9.

12 Beaufrere B, Beylot M, Metz C, et al. Dawn phenomenon in type 1 (insulin-dependent) diabetic adolescents: influence of nocturnal growth hormone secretion. Diabetologia 1988 31:607-1

13 Walsh CH, O'Sullivan DJ. Carbohydrate tolerance during the menstrual cycle in diabetics. Lancet 1973;ii:413-5. 